\title{
Antifibrotic Activity of Phaleria macrocarpa Extract in Rat Liver-fibrosis Model: Focus on Oxidative Stress Markers, TGF- $\beta 1$ and MMP-13
}

\author{
Bantari W. K. Wardhani ${ }^{1}$, Nanik Sundari ${ }^{2}$, Raymond R. Tjandrawinata ${ }^{3}$, Ahmad Aulia Jusuf ${ }^{4}$, Vivian Soetikno ${ }^{5}$, Melva Louisa $^{5 \star}$
}

${ }^{1}$ Doctoral Program in Biomedical Sciences, Faculty of Medicine, Universitas Indonesia, Depok, Indonesia; ${ }^{2}$ Master Program in Biomedical Sciences, Faculty of Medicine, Universitas Indonesia, Depok, Indonesia; ${ }^{3}$ Dexa Laboratories of Biomolecular Sciences Unit, Dexa Medica Group, Cikarang, West Java, Indonesia; ${ }^{4}$ Department of Histology, Faculty of Medicine, Universitas Indonesia, Depok, Indonesia; ${ }^{5}$ Department of Pharmacology and Therapeutics, Faculty of Medicine, Universitas Indonesia, Depok, Indonesia

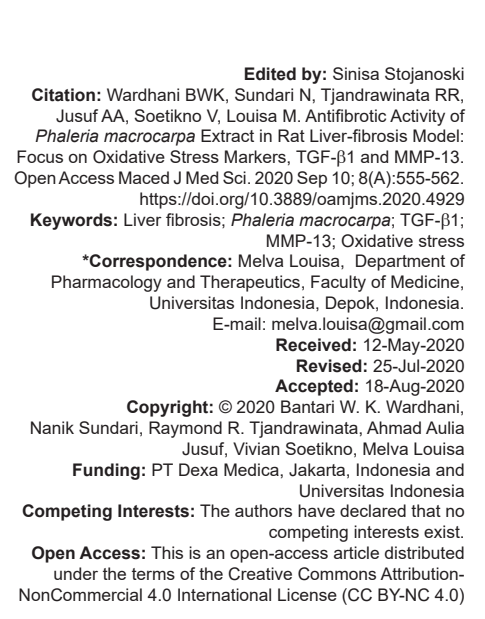

\section{Abstract}

AIM: This study was aimed to determine the antifibrotic activity of Phaleria macrocarpa (PM) extract in liver fibrosis (LF) and its possible mechanism in the rat model.

METHODS: Sprague Dawley male rats were injected with $2 \mathrm{~mL} / \mathrm{kg}$ BW of carbon tetrachloride intraperitoneally twice a week for 2 weeks, followed by $1 \mathrm{~mL} / \mathrm{kg}$ BW for 6 weeks. Afterward, the treatments began from the $3^{\text {rd }}$ week: Silymarin $100 \mathrm{mg} / \mathrm{kg} \mathrm{BW/day,} \mathrm{standardized} \mathrm{PM} \mathrm{extract} \mathrm{(Proliverenol)} 75$ or $150 \mathrm{mg} / \mathrm{kg} \mathrm{BW/day} \mathrm{orally.} \mathrm{Rats} \mathrm{were}$ sacrificed in the $8^{\text {th }}$ week. Blood and liver were collected to analyze liver function, liver damage and fibrosis marker, oxidative stress markers, pro-fibrogenic cytokine, and antifibrotic marker.

RESULTS: Our study showed that the treatment of silymarin and PM resulted in the normalized activity of liver function, followed by the amelioration of oxidative stress, demonstrated by the decreased malondialdehyde levels and an increased ratio of glutathione and glutathione disulfide. All markers examined showed that PM extract has antioxidant activity due to decreased hepatic stellate cell activation. We also found a decrease in tumor growth factors- $\beta 1$ and protein expressions of matrix metalloproteinases- 13 in all treatment groups compared to the carbon tetrachloride group. There were tendencies of the decreased fibrotic area following improvements of biochemical parameters.

CONCLUSION: PM extracts ameliorate carbon tetrachloride-induced LF. The proposed mechanism is by overcoming oxidative stress and regulating pro-fibrogenic cytokine and antifibrotic markers.

\section{Introduction}

Liver fibrosis (LF) is a long-lasting injury and inflammation in the liver. Scarring of the LF may lead to life-threatening complications such as cirrhosis and hepatocellular carcinoma (HCC) [1], [2]. LF is associated with a $45 \%$ mortality rate in Europe and the most common cause of non-neoplastic death in the United States [2], [3], [4]. Up to date, there are no antifibrotic agents available in the market. The approach used to treat LF is by managing the underlying disease [1], [3], [5].

Phaleria macrocarpa (PM) (Scheff.) Boerl., namely, Mahkota Dewa in Indonesia, is a member of the family Thymelaeaceae. Pits, stems, leafage, and fruits of PM were widely used as natural sources of medical plants in Indonesia [6]. PM, mainly grains, has been used empirically to treat cancer, allergy, and diabetes mellitus [6], [7]. Many studies have elucidated the chemical compounds of PM, which consists of mahkoside A, mangiferin, kaempferol-3$O-\beta$-glucoside, dodecanoic acid, palmitic acid, ethyl stearate, fevicordin-A, and sucrose [6], [7], [8]. PM also has been studied for its antioxidant, anti-inflammatory, cytotoxicity, antihistamine, and hepatoprotective effects [7], [8], [9].

The hepatoprotective activity of this PM extract was reported by Berlian et al. [10] using in vitro ethanol-induced LF model. PM extracts suppressed the expressions of NF-KB, TNF- $\alpha$, and caspase-8 [10]. Hendra et al. [6] also reported that PM fruit extract has antioxidant and anti-inflammation using an in vitro model. Antioxidant was proven by ferric thiocyanate (FTC), thiobarbituric acid (TBA), and 2,2-diphenyl-1picrylhydrazyl (DPPH) assay. The anti-inflammatory effect was determined by nitric oxide (NO) inhibitory effect [6]. In accordance with their results, Sundari et al. [9] confirmed the protective effect using the in vivo model. PM extracts prevent $\mathrm{CCl}_{4}$-induced fibrosis 
through its antioxidant and anti-inflammatory activities [9]. Other studies also reported that the upregulation of the NF-kB transduction pathway and lipid peroxidation is critical in LF [1], [2], [3], [11]. Considering all the above facts, we presume that PM extracts might have the antifibrotic activity to attenuate LF. Hence, this study was aimed to determine the antifibrotic activity of $\mathrm{PM}$ extracts and investigate its mechanism in carbon tetrachloride-induced LF in male rats.

\section{Materials and Methods}

\section{silymarin \\ PM aqueous extract (Proliverenol) and}

The dried powder PM extract (Proliverenol) was prepared by Dexa Laboratories of Biomolecular Sciences (Batch No. RP130116), as described by Kim et al. [8] and Berlian et al. [10]. Proliverenol was a bioactive fraction extracted from $P$. macrocarpa fruit using subcritical water extraction, as described by Kim et al. [8]; Berlian et al. [10]; and Sundari et al. [9]. Slivers of PM fruits were macerated using water-based solvent and carried out extraction under temperatures of $373 \mathrm{~K}$, pressures $4.0 \mathrm{MPa}$ for $5 \mathrm{~h}$. The yield extract was then filtered, evaporated, dried, and collected in a tube. High purity silymarin $(81.32 \%)$ was purchased from Plamed Science Technology Company (Xian, China).

\section{Experimental design}

Sprague Dawley male rats (200-350 g) were maintained on a 12-h light/dark cycle and allowed free access to food and water. The protocol was approved by the Animal Care Ethics Committee from the Faculty of Medicine, Universitas Indonesia. The flow of the experiments done in the study is depicted in Figure 1. The total sample in this experiment is 25 rats divided into five groups. The number of rats per group was decided based on sample calculation by Charan et al. [12]. Five rats were allocated to a healthy control group. The other 20 rats were treated with an intraperitoneal injection of $2 \mathrm{~mL} / \mathrm{kg} \mathrm{CCl}$ (carbon tetrachloride, Merck, Germany) in olive oil (1:1) twice weekly for first 2 weeks and followed by $1 \mathrm{~mL} / \mathrm{kg}$ weight for 6 weeks [13], [14], [15]. The 20 rats of the liverfibrosis induced were randomly divided into four groups of five rats: $\mathrm{CCl}_{4}$ only (untreated liver-fibrosis model); $\mathrm{CCl}_{4}$ + silymarin $100 \mathrm{mg} / \mathrm{kg} /$ day (Sil), $\mathrm{CCl}_{4}$ plus PM extract 75 (T75), and $\mathrm{CCl}_{4}$ plus $150 \mathrm{mg} / \mathrm{kg} /$ day (T150) orally on the $3^{\text {rd }}$ week. After 8 weeks, all animals were sacrificed by decapitation (3 days after the last injection of $\mathrm{CCl}_{4}$ ) [14].

\section{Biochemistry analysis}

The whole blood was collected in a heparin tube and centrifuged 3000 rpm for $10 \mathrm{~min}$ [16]. Obtained plasma was analyzed for alanine transaminase $(\mathrm{ALT})$, aspartate transaminase (AST), and alkaline phosphatase (ALP). Those were quantified using kit DiaSys (Int. Holzheim, Germany). Liver tissue was homogenized and used for oxidative stress and concentrations of TGF- $\beta 1$. Oxidative stress was determined by the MDA level and GSH/GSSG ratio. MDA level was analyzed by thiobarbituric acid (TBA) assay, while GSH/GSSG ratio was measured according to the manufacturer's protocol (Cell Biolabs Inc, San Diego, USA). The concentration of TGF- $\beta 1$ in liver tissue was quantified using ELISA kit TGF- $\beta 1$ according to the manufacturer's protocol (Novateinbio, MA, USA).

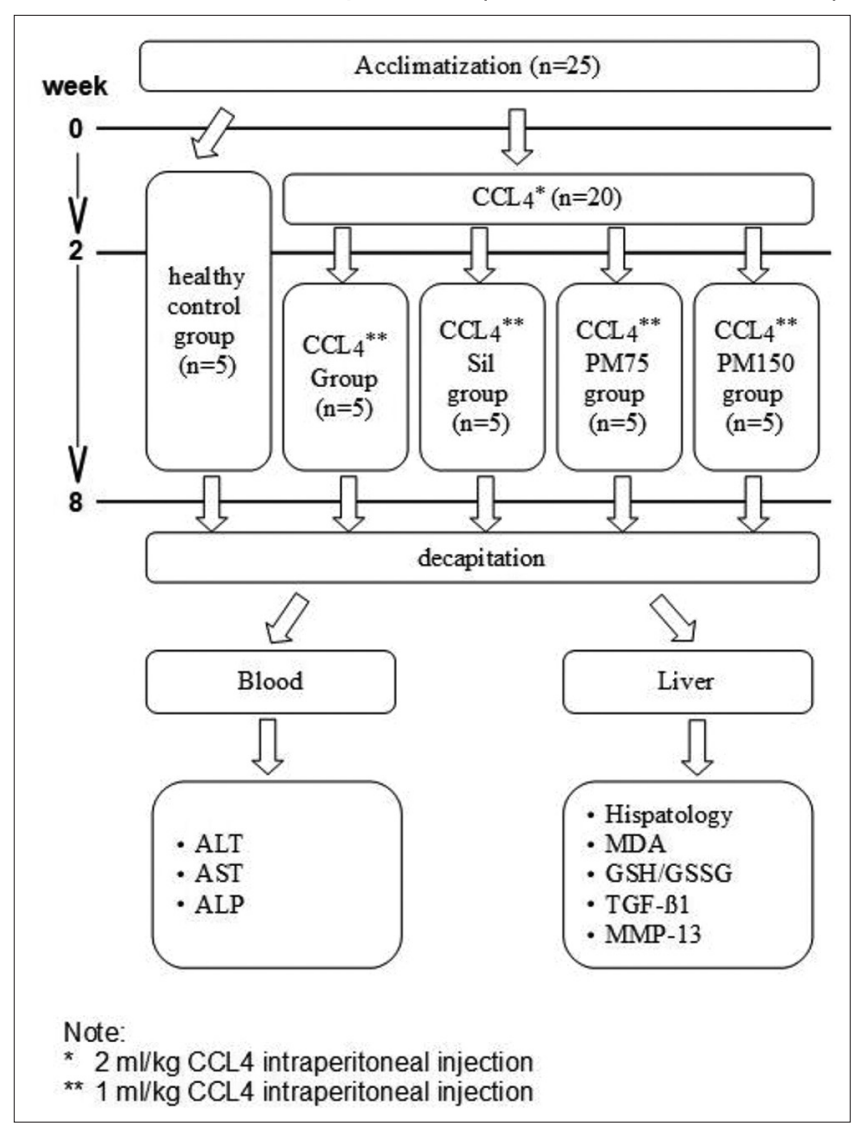

Figure 1: The flow of experiments throughout the study. $\mathrm{CCl}_{4}$ : Carbon tetrachloride, Sil: Silymarin $100 \mathrm{mg} / \mathrm{kg} / \mathrm{day}, \mathrm{T75}$ : PM extract 75 mg/kg/day; T150: PM extract $150 \mathrm{mg} / \mathrm{kg} /$ day. $\mathrm{n}$ : number of rats

\section{analysis}

Histopathology and Immunohistochemistry

Section of the area around central vein from all rat livers was sliced, fixed in $10 \%$ buffered formalin, and made in a paraffin-embedded block. Histopathology analysis was done to determine the accumulation of connective tissue by Masson's trichrome staining [17]. While MMP-13 was detected by immunohistochemistry, as described in the manufacturer's procedure using primary antibody from Santa-Cruz (sc-101564, USA) and Novolink ${ }^{\mathrm{TM}}$ Polymer Detection System from Leica Biosystems (RE7290-K, USA). We analyzed the degree of fibrosis in histopathology and assessed quantitatively using the J-Image software image processor. 


\section{Statistical analysis}

All the graphs and statistical tests were done using GraphPad Prism 8 (USA) software. The results were expressed as mean \pm standard deviation (SD). The differences among groups were analyzed by one-way analysis of variance (ANOVA) and followed by post hoc Tukey analysis when data were normally distributed and had homogeneous variance. Kruskal-Wallis followed by Mann-Whitney tests were used when the data did not meet the requirement for parametric analysis. A $p<0.05$ is considered statistically significant.

\section{Results}

After 8 weeks of $\mathrm{CCl}_{4}$ administration, the $\mathrm{CCl}_{4}$ group showed a significant increase in ALT, AST, and ALP activity in plasma as hepatic injury markers. Sil, $\mathrm{T} 75$, and T150 groups showed ameliorated all of the markers significantly (Figure 2).

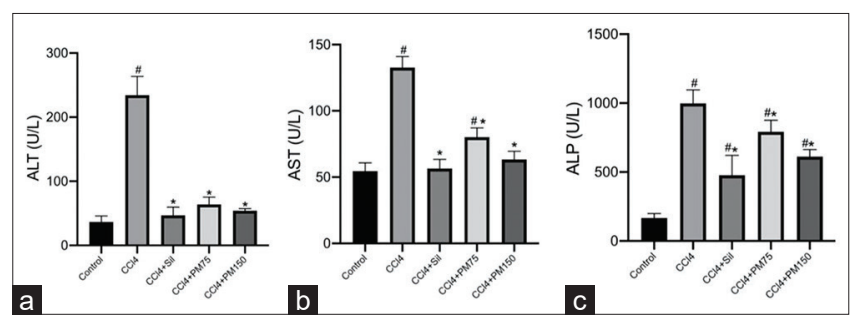

Figure 2: Silymarin and Phaleria macrocarpa extracts enhance the activity of (a) ALT, (b) AST, and (c) ALP after 8 weeks of $\mathrm{CCl}_{4}$-induced LF. Data are expressed as mean $\pm S D$. $\mathrm{CCl}_{4}$ : Carbon tetrachloride, Sil: Silymarin 100 mg/kg/day, T75: PM extract 75 mg/kg/day; T150: $P M$ extract $150 \mathrm{mg} / \mathrm{kg} /$ day. ${ }^{\#} p<0.05$ versus control group; ${ }^{*} p<0.05$ versus $\mathrm{CCl}_{4}$ group. There was a significant decrease in the activity of $A L T, A S T$, and ALP in silymarin and PM extracts as compared to the $\mathrm{CCl}_{4}$ group. Silymarin decreased the activity of $A L T$ and AST, approaching the values of those in the control group

Our findings in the liver function markers are supported with histopathology results, as shown in Figure 3.

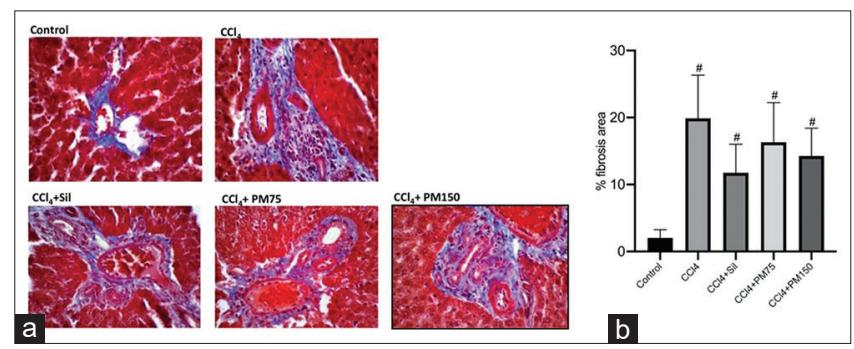

Figure 3: Silymarin and Phaleria macrocarpa extract attenuated the effect of 8-week of $\mathrm{CCl}_{4}$-induced liver fibrosis by decreasing fibrosis area. (a) Histopathology overview, which represents each treatment group using Masson's Trichrome Staining (magnification: $\times 400$ ). The blue color represents an accumulation of connective tissue surrounding area branches of the hepatic artery, portal vein, and bile duct. (b) Quantification results of fibrosis area using image processor. Data are expressed as mean $\pm S D$. $\mathrm{CCl}_{4}$ : Carbon tetrachloride, Sil: Silymarin 100mg /kg/day, T75: PM extract 75 mg/kg/day; T150: PM extract 150 mg/kg/day. ${ }^{*} p<0.05$ versus control group; ${ }^{*} p<0.05$ versus $\mathrm{CCl}_{4}$ group

The percentage of fibrosis area in the $\mathrm{CCl}_{4}$ treated group resulted in fibrosis was significantly increased as compared to normal. Silymarin and PM extract reduced the percentage of fibrotic areas, although the decline had not approached the control group.

LF induced by $\mathrm{CCl}_{4}$ was clearly shown in the $\mathrm{CCl}_{4}$ group, with a significant increase in the area of fibrosis and hepatic oxidative stress marker (MDA) as compared to the control group (Figure 4a). The GSH/ GSSG ratio was shown to decline to compensate for oxidative stress that occurs on LF pathogenesis. Both silymarin and PM extracts in two different doses ameliorate fibrosis area, reduced MDA levels, and increased the GSH/GSSG ratio significantly compared to the $\mathrm{CCl}_{4}$ group (Figure $4 \mathrm{~b}$ ).

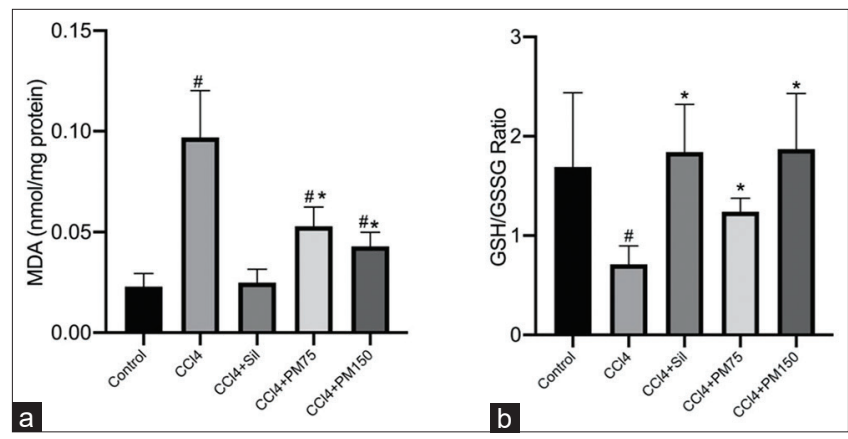

Figure 4: Silymarin and Phaleria macrocarpa extracts improve oxidative stress markers in $\mathrm{CCl}_{4}$-induced liver fibrosis as shown by (a) malondialdehyde levels, (b) ratio of GSH/GSSG Data are expressed as mean $\pm S D$. $\mathrm{CCl}_{4}$ : Carbon tetrachloride, Sil: Silymarin $100 \mathrm{mg} / \mathrm{kg} /$ day, T75: PM extract $75 \mathrm{mg} / \mathrm{kg} /$ day; T150: PM extract $150 \mathrm{mg} / \mathrm{kg} /$ day. ${ }^{\#} p<0.05$ versus control group; ${ }^{*} p<0.05$ versus $\mathrm{CCl}_{4}$ group

Data are expressed as mean \pm SD. $\mathrm{CCl}_{4}:$ Carbon tetrachloride, Sil: Silymarin $100 \mathrm{mg} / \mathrm{kg} / \mathrm{day}$, T75: PM extract $75 \mathrm{mg} / \mathrm{kg} /$ day; T150: PM extract $150 \mathrm{mg} / \mathrm{kg} / \mathrm{day}$. ${ }^{\#} p<0.05$ versus control group; ${ }^{*} p<0.05$ versus $\mathrm{CCl}_{4}$ group.

Chronic $\mathrm{CCl}_{4}$ administration for 8 weeks increased the TGF- $\beta 1$ levels and in line to a percentage of the positive expressions of MMP-13. Sil and PM extracts ameliorate levels of TGF- $\beta 1$ and reduced the percentage of the positive expressions of MMP-13 (Figure 5).

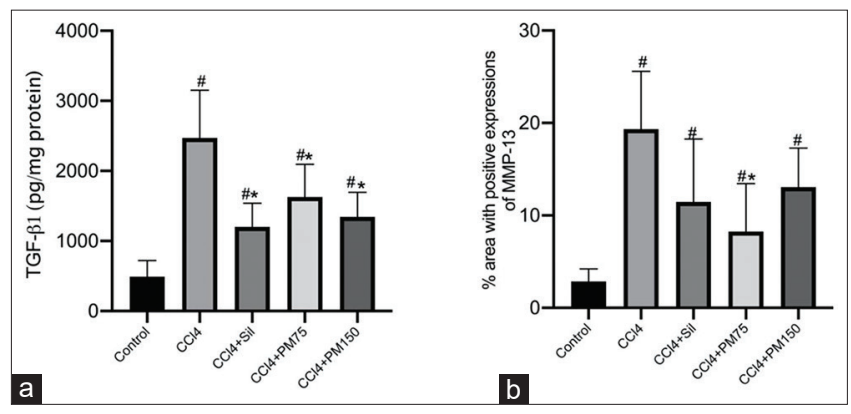

Figure 5: Phaleria macrocarpa extracts elevated (a) levels of TGF- $\beta 1$ and (b) the percentage of area with positive expressions of MMP-13 (immunohistochemistry). Data are expressed as mean $\pm S D$. $\mathrm{CCl}_{4}$ : Carbon tetrachloride, Sil: Silymarin $100 \mathrm{mg} / \mathrm{kg} /$ day, T75: PM extracts $75 \mathrm{mg} / \mathrm{kg} /$ day; T150: PM extracts $150 \mathrm{mg} / \mathrm{kg} /$ day. ${ }^{*} p<0.05$ versus control group; * $p<0.05$ versus $\mathrm{CCl}_{4}$ group 


\section{Discussion}

The present study aimed to investigate PM extracts' efficacy and mechanism for the treatment of LF. $\mathrm{CCl}_{4}$ was used to induce LF that involved oxidative stress and followed persistent inflammation as same as happened in chronic liver disease [12], [13], [14]. Chronic administration of $\mathrm{CCl}_{4}$ for 8 weeks caused liver damage characterized by an increase of ALT, AST, and ALP activity in plasma. As described by Hayashmi et al. [12], Truong et al. [16], and Li L et al., [18], the mechanism of $\mathrm{CCl}_{4}$ is trichloromethyl and trichloromethyl peroxide radicals is attacked the endoplasmic reticulum membrane and leading to lipid peroxidation [12], [16], [18]. $\mathrm{CCl}_{4}$ chronic treatments lead to impaired membrane permeability so that the enzymes in the cytosol and mitochondria of hepatocytes will come out into plasma. Consequently, there are increased activities of those in plasma [16].

ALT and AST are enzymes located in the cytosol of hepatocytes that are involved in the gluconeogenesis process. Hepatocyte injury can lead to increased activity of them up to more than 2 times normal [18]. [19], [20]. We showed a significant increase in ALT and AST enzyme activity in the $\mathrm{CCl}_{4}$ group, more than 2 times from normal value. These results are in line with other studies by Constandinou et al. [13], Tzeng et al. [21], Bona et al. [22], and Deng et al. [23]. In contrast to our results, Tsai et al. [24] reported that the treatment of $\mathrm{CCl}_{4}$ only caused an increase of ALT and AST less than twice compared to the control group, though they found clear signs of LF in histopathology samples.

ALP is an enzyme that catalyzes the hydrolysis process of organic phosphate to inorganic phosphate. Increased activity of ALP for 3-10 times from normal value is the result of cholestasis and obstruction of intra and extra biliary [16]. $\mathrm{CCl}_{4}$ in this study has caused an increase of ALP activity more than 3 times the standard value. It indicated that chronic administration of $\mathrm{CCl}_{4}$ causes bile duct disorders. These results are consistent with the findings by other researchers similar to Bona et al. [22], Tuncer et al. [25], and Amin et al. [26] that used $\mathrm{CCl}_{4}$ to induce fibrosis.

The increase in the three markers showed signs of chronic injury of the liver caused by $\mathrm{CCl}_{4}$, which is a good fibrosis model. This fibrosis model was used to study PM extract's antifibrotic activity ( 75 and $150 \mathrm{mg} / \mathrm{kg} /$ day). Doses used in this study were determined from the previous research [9], [10]. Silymarin (Sil) has been reported to stop the progression of LF effectively in vitro and in vivo by improving histopathology and decreased biochemical parameters [24], [27]. It has been used for patients who have NAFLD and alcoholic liver disease (ALD). It improved biochemical parameters (AST, ALT, and GGT), ameliorate inflammation through the reduction in TNF- $\alpha$ serum levels, and decrease hepatic steatosis degree, which followed by improvement in histopathology [28], [29]. Silymarin is leading to inhibit HSCs activation and protect hepatocytes from apoptosis when oxidative stress occurs in LF [3], [27]. Silymarin was known to scavenge free radicals, thereby inhibiting lipid peroxidation. It also has an anti-inflammatory effect by inhibiting intrahepatic activation of the transcription factor NF-kB. Thus, decreasing the release of TNF- $\alpha$, IFN- $\gamma$, IL-2, and inducible NO synthase (iNOS) that plays a role in the process of chronic inflammation as well as LF [29], [30]. In the previous study, PM extract inhibits the NF-kB pathway and decreases lipid peroxidation [9], [10]. Therefore, silymarin was chosen as a comparator. In line with our findings, a study by Mostafa et al. reported that the administration of silymarin $100 \mathrm{mg} / \mathrm{kg} / \mathrm{day}$ decreased ALP activity significantly compared with the fibrosis group [31]. Studies by Tsai et al. and Amin et al. had also shown a decrease in ALP enzyme activity after administration of silymarin $200 \mathrm{mg} / \mathrm{kg}$ [24], [26].

Improvement in liver function tests by all treatment groups was in line with the findings in the percentage of fibrosis area. In agreement with our study, Tsai et al. [24], Amin et al. [22], and Lee et al. [32] reported that the administration of silymarin caused liver improvement in histopathology examination.

$\mathrm{CCl}_{4}$ leads to oxidative stress, causes damage to hepatocytes, and further induces fibrogenesis in chronic exposure [13], [16], [18]. Imbalance redox status occurred due to the increased free radicals from $\mathrm{CCl}_{4}$ metabolites and the lack of endogenous antioxidant capacity. Those were described by elevation MDA levels (lipid peroxidation) and declining GSH/GSSG ratio (endogenous antioxidant capacity) [33], [34], [35]. MDA levels were higher in $\mathrm{CCl}_{4}$ than the control group, which showed elevation of lipid peroxidation. All therapy groups improved the level of MDA. CCl4 produced those due to their ability to scavenge free radicals, thus inhibiting lipid peroxidation in hepatocytes [10], [27], [30]. GSH/GSSG ratio declined in the $\mathrm{CCl}_{4}$ group compared to the control group. Silymarin and PM extract improved GSH/GSSG ratio, which is higher than the $\mathrm{CCl}_{4}$ group and approached the control group. Studies done by Tzeng et al. [21] and Kiruthiga et al. [36] showed that silymarin increased endogenous antioxidant activity by improving the glutathione peroxidase activity (GPx), manganese superoxide dismutase (Mn-SOD), and cooper/zinc-superoxide dismutase (Cu/Zn-SOD) [21], [36]. The increase of endogenous antioxidant activity illustrated elevation GSH availability to form conjugates with $\mathrm{CCl} 300^{\circ}$ and $\mathrm{COCl}_{2}$ (free radical, which is $\mathrm{CCl}_{4}$ metabolites). The antioxidant activity of the PM extract might mediate the anti-fibrosis effect.

The possible mechanism of antifibrotic activity is by regulating TGF- $\beta 1$ and MMP-13. Decreased TGF$\beta 1$ levels reduce the activation of hepatic stellate cells, which further inhibits fibrogenesis. While as a marker for antifibrotic activity, we measure MMP-13, which acts by degrading ECM in LF [13], [37], [38]. We found that silymarin and PM extracts reduced the TGF- $\beta 1$ levels. However, the improvement has not reached the normal 
level, which indicates that silymarin and PM treatment have not been able to normalize TGF- $\beta 1$ levels. In line with our findings, Li et al. [39] showed the decline of TGF- $\beta 1$ in a higher dose $(200 \mathrm{mg} / \mathrm{kg} /$ day $)$, and longer duration of silymarin still could not normalize profibrotic cytokines. Reversal of LF normalization has also not been successful with other drugs such as pioglitazone and phloridzin [14], [23].

MMP-13 is a specific protease capable of degrading collagen type I in rodents [10], [14], [34]. MMP-13 in rodents has functions similar to MMP-1 in humans and is required to maintain the homeostasis of ECM on rodents [40], [41].

In LF, Kupffer cells, hepatic stellate cells, and activated myofibroblast will produce MMP-13 for degrading collagen I, resulting in decreased ECM composition [13], [40]. We showed an elevation percentage of the positive expressions of MMP-13 in the $\mathrm{CCl}_{4}$ group, even not approaching the healthy group. This finding was in agreements with studies done by Iridale et al. [40] and Chen et al. [42] Iridale et al. reported that the expression of MMP-13 increases in experimental fibrosis model, which is induced by $\mathrm{CCl}_{4}$ intraperitoneally in the same regimen in this study for 4 weeks [41]. The decline was not as apparent as the improvement of histopathology examination [41]. While Chen et al. reported that there were increased expressions of MMP-2, MMP-8, MMP-9, MMP-13, TIMP-1, and TIMP-2 in the fibrosis model group due to administration of TAA [42].

Iridale et al. [40] and Leclercq et al. [14] found that $\mathrm{CCl}_{4}$ induction similar dose in this study can increase MMP-13, which differs significantly from the control group. Ginanndrea et al. [43] reported that in the early phase of fibrogenesis, and myofibroblast activation occurs, followed by the release of proinflammatory cytokines (such as TNF- $\alpha$ and IL-1) and pro-fibrogenic cytokines (TGF- $\beta 1$ ). TNF- $\alpha$ induces activation and expression of MMP-13. Both cytokines are released by extra-hepatic macrophages, Kupffer cells, and HSCs when activated [40], [43]. Uchinami reported that the elevation TNF- $\alpha$ during peak LF is accompanied by increased expression of MMP-13 [44]. In our experiments, the MMP-13 in the $\mathrm{CCl}_{4}$ group was increased. As described by Iridale et al. [40] and Uchinami et al. [44], it possibly occurred due to the continuous activation of hepatic stellate cells, which resulted in myofibroblast activation.

There was a tendency to decline in the positive expressions of MMP-13 in all treatment groups, silymarin, and PM extracts. The phenomenon might occur due to inhibition of hepatic stellate cells and myofibroblast activation by silymarin and PM extract. Therefore, activation of MMP-13-producing cells has decreased, although those are higher than the control group. It is in accordance with a study, which is conducted by Chen et al. [42]. They reported that silymarin could reduce the expression of MMP-13.
In contrast, Leclercq et al. [14] reported that pioglitazone for 3 weeks and 7 weeks led to MMP-13 elevation, which was significantly different compared to the $\mathrm{CCl}_{4}$ group and baseline [14]. Another study done by Kawaguchi et al. found that pioglitazone could prevent the activation of HSCs by reducing the mRNA expression of collagen type I, MMP-2, TIMP-1, and TIMP-2 and increased the expression of MMP-13 mRNA [41]. However, an in vivo study by Kawaguchi et al. showed declining mRNA expression of TIMP-1 and TIMP-2 with no increase in MMP-13 [45].

MMP-13 alone could not adequately describe the process of ECM degradation. However, the process of ECM degradation can be seen from the percentage of fibrosis area. It tends to decrease, although not significant, compared to the $\mathrm{CCl}_{4}$ group. It happened because there are two working mechanisms of MMP-13. First, MMP-13 will directly degrade collagen types I and III then resulting in decreased ECM accumulation. Its process is leading to LF resolution [40], [41], [42], [43], [46]. Second, MMP-13 can activate pro-HGF (hepatocytes progrowth factors) to HGF. HGFs bind to the c-Met receptor and subsequently induce the expression of MMP-2 and MMP-9 [47]. In accordance, Iridale et al. showed that increasing MMP-13, followed by decreasing of TIMP-1 and TIMP-2 in fibrosis [40]. Then, the expressions of TIMP-1 and TIMP-2 reduce when LF occurs without MMP-13 reduction [40].

Furthermore, the presence of proinflammatory (TNF- $\alpha$ and IL-1) and pro-fibrogenic (TGF- $\beta 1$ ) cytokines can affect the expression of MMPs and TIMP [40], [44]. Elevation of pro-inflammatory cytokines, lead to the induced expression of MMP-13. Nevertheless, pro-fibrogenic cytokine PM extract at T75 and T150 groups decreases the activity of ALT and AST significantly compared to the $\mathrm{CCl}_{4}$ group. Our findings are consistent with results from the previous study, in which proven PM extract is shown to ALT and AST activity in rats induced ethanol [9], [11]. ALP levels decreased in all treatment groups, however, not enough to reach the value of the control group. Mostafa et al. [31] reported the administration of Sil, $100 \mathrm{mg} / \mathrm{kg} /$ day decreased ALP activity significantly compared with the fibrosis group $\left(\mathrm{CCl}_{4}\right)$ to near normal values. TGF- $\beta 1$ only induced expression of TIMPs, not MMPs [40], [47], [48]. Thereby, silymarin and PM extracts have improved liver function test markers through decreased ALT, AST, and ALP activity, followed by oxidative stress markers improvement through declined MDA levels and as the elevation of GSH/GSSG ratio.

PM extracts are shown to have antioxidative activity by the prevention of hepatocyte damage due to $\mathrm{CCl}_{4}$. The antioxidant activity may decrease HSCs activation and myofibroblast and further decrease the pro-fibrogenic cytokine (TGF- $\beta 1$ ) has decreased. Along with that, expressions of MMP-13 declined in all treatment groups compared to the $\mathrm{CCl}_{4}$ group. This 
shows PM extracts' antifibrotic activity on LF reversal through the improvement of all the biochemical parameters, followed by the tendency to decrease the fibrosis percentage area. The activation of HSCs by PM was not determined, which was the limitation of our study. This activation has a pivotal role in LF. Therefore, it remains unclear the mechanism of PM extract on HSCs activation, as well as TIMPs and MMPs regulation.

\section{Conclusion}

PM extract has anti-fibrosis by improving liver functions (AST and ALP), declining MDA levels, elevating GSH/GSSG ratio, decreasing TGF- $\beta 1$ concentrations, and MMP-13 expressions. However, these effects were not enough to normalize the fibrosis effect.

\section{Data availability statement}

All the data used to support this study's findings are available from the corresponding author on request.

\section{Acknowledgment}

The authors would like to thank PT Dexa Medica (Jakarta, Indonesia) for funding this study, Universitas Indonesia for International Publication grant and drh. Vetnizah Juaniantito, Ph.D. from Bogor Agricultural University, Faculty of Veterinary Medicine, Bogor, Indonesia, for helping us in immunohistochemistry work.

\section{References}

1. Cohen-Naftaly M, Friedman SL. Current status of nove antifibrotic therapies in patients with chronic liver disease. Therap Adv Gastroenterol. 2011;4(6):391-417. https://doi. org/10.1177/1756283×11413002 PMid:22043231

2. Wick G, Grundtman C, Mayerl C, Wimpissinger TF, Feichtinger J, Zelger B, et al. The immunology of fibrosis. Annu Rev Immunol. 2013;31:107-35. https://doi.org/10.1146/ annurev-immunol-032712-095937

PMid:23516981

3. Battaller R, Brenner A. Liver fibrosis. J Clin Invest. 2005;115(2):209-18.

PMid: 15690074
4. Gressner OA, Weiskirchen R, Gressner AM. Evolving concepts of liver fibrogenesis provide new diagnostic and therapeutic options. Comp Hepatol. 2007;6:7. https://doi. org/10.1186/1476-5926-6-7

PMid:17663771

5. Manka P, Zeller A, Syn W. Fibrosis in chronic liver disease: An update on diagnostic and treatment modalities. Drugs. 2009;79(9):903-27. https://doi.org/10.1007/ s40265-019-01126-9

\section{PMid:31119644}

6. Hendra R, Ahmad S, Oskouian E, Sukari A, Shukor MY Antioxidant, anti-inflammatory and cytotoxicity of Phaleria macrocarpa (Boerl.) Scheff fruit. BMC Complement Altern Med. 2011;11:1-10. https://doi.org/10.1186/1472-6882-11-110 PMid:22070850

7. Zhang $\mathrm{Y}, \mathrm{Xu} \mathrm{X}$, Liu $\mathrm{H}$. Chemical constituents from mahkota dewa. J Asian Nat Prod Res. 2006;8(1-2):119-23.

PMid:16753792

8. Kim WJ, Veriansyah B, Lee YW, Kim J, Kim JD. Extraction of mangiferin from mahkota dewa (Phaleria macrocarpa) using subcritical water. J Ind Eng Chem. 2010;16(3):425-30. https:// doi.org/10.1016/j.jiec.2009.08.008

9. Sundari N, Soetikno V, Louisa M, Wardhani BW, Tjandrawinata RR. Protective effect of Phaleria macrocarpa water extract (Proliverenol) against carbon tetrachloride-induced liver fibrosis in rats: Role of TNF- $\alpha$ and TGF- $\beta$ 1. J Toxicol. 2018;2018:2642714. https://doi.org/10.1155/2018/2642714 PMid:30631351

10. Berlian G, Tjandrasasmita OM, Tjandrawinata RR. Standardized bioactive fraction of Phaleria macrocarpa (Proliverenol) prevents ethanol-induced hepatotoxicity via down-regulation of the NF-kB-TNF $\alpha$-caspase-8 pathway. Asian Pac J Trop Biomed. 2016;6(8):686-91. https://doi.org/10.1016/j.apjtb.2016.06.007

11. Cong M, Iwasaki K, Jiang C, Kisseleva T. Cell signals influencing hepatic fibrosis. Int J Hepatol. 2012;2012:158547.

PMid:22973518

12. Charan J, Katharia ND. How to calculate sample size in animal studies? J Pharmacol Pharmacother. 2013;4(4):303-6. https:/ doi.org/10.4103/0976-500x.119726

PMid:24250214

13. Hayashi H, Sakai T. Animal models for the study of liver fibrosis: New insights from knockout mouse models. Am J Physiol Gastrointest Liver Physiol. 2011;300(5):G729-38. https://doi. org/10.1152/ajpgi.00013.2011

PMid:21350186

14. Constandinou C, Henderson N, Iredale JP. Modeling liver fibrosis in rodent. Methods Mol Med. 2005;117:237-50. PMid: 16118456

15. Leclercq IA, Sempoux C, Stärkel P, Horsmans Y. Limited therapeutic efficacy of pioglitazone on progression of hepatic fibrosis in rats. Gut. 2006;55(7):1020-9. https://doi.org/10.1136/ gut.2005.079194

PMid: 16484506

16. Truong N, Nguyen NH, Nguyen NT, Le H, Tran G, Huynh N et al. Establishment of a standardized mouse model of hepatic fibrosis for biomedical research. Biomed Res Ther. 2014;1(2):43-9. https://doi.org/10.7603/s40730-014-0009-2

17. Standish RA, Cholongitas E, Dhillon A, Burroughs AK, Dhillon AP. An appraisal of the histopathological assessment of liver fibrosis. Gut. 2006;55(4):569-78. https://doi.org/10.1136/ gut.2005.084475 PMid:16531536

18. Li L, Hu Z, Li W, Hu M, Ran J, Chen P, et al. Establishment of a standardized liver fibrosis model with different pathological 
stages in rats. Gastroenterol Res Pract. 2012;2012:560345. https://doi.org/10.1155/2012/560345

PMid:22761610

19. Luedde T, Kaplowitz N, Schwabe RF. Cell death and cell death responses in liver disease: Mechanisms and clinical relevance. Gastroenterology. 2014;147(4):765-83. https://doi. org/10.1053/j.gastro.2014.07.018

PMid:25046161

20. Fallatah HI. Noninvasive biomarkers of liver fibrosis: An overview. Adv Hepatol. 2014;2014:357287.

21. Tzeng JI, Chen MF, Chung HH, Cheng JT. Silymarin decreases connective tissue growth factor to improve liver fibrosis in rats treated with carbon tetrachloride. Phytother Res. 2013;27(7):1023-8. https://doi.org/10.1002/ptr.4829 PMid:22933420

22. Bona S, Filippin LI, Naso FC, David C, Valiatti B, Schaun MI, et al. effect of antioxidant treatment on fibrogenesis in rats with carbon tetrachloride-induced cirrhosis. ISRN Gastroenterol. 2012;2012:762920. https://doi.org/10.5402/2012/762920

23. Deng G, Wang J, Zhang Q, He H, Wu F, Feng T, et al. Hepatoprotective effects of phloridzin on hepatic fibrosis induced by carbon tetrachloride against oxidative stress-triggered damage and fibrosis in rats. Biol Pharm Bull. 2012;35(7):111825. https://doi.org/10.1248/bpb.b12-00057

PMid:22791160

24. Tsai JH, Liu JY, Wu TT, Ho PC, Huang CY, Shyu JC, et al. Effects of silymarin on the resolution of liver fibrosis induced by carbon tetrachloride in rats. J Viral Hepat. 2008;15(7):508-14. https:// doi.org/10.1111/j.1365-2893.2008.00971.x

PMid: 18397225

25. Tuncer I, Ozbek H, Urgas S, Bayram I. Anti-fibrogenic effects of captopril and candesartan cilexetil on the hepatic fibrosis development in rat. The effect of AT1-R blocker on the hepatic fibrosis. Exp Toxicol Pathol. 2003;55(2-3):159-66. https://doi. org/10.1078/0940-2993-00309

PMid: 14620537

26. Amin A, Ghoneim AM. Texture analysis of liver fibrosis microscopic images: A study on the effect of biomarkers. Acta Biochim Biophys Sin (Shanghai). 2011;43(3):193-203. https:// doi.org/10.1093/abbs/gmq129

PMid:21258076

27. Abenavoli L, Izzo A, Milic N, Cicala C, Santini A, Capasso R. Milk thistle (Silybum marianum): A concise overview on its chemistry, pharmacological, and nutraceutical uses in liver diseases. Phytother Res. 2018;32(11):2202-13. https://doi.org/10.1002/ ptr.6171

PMid:30080294

28. Kheong CW, Mustapha NR, Mahadeva S. A randomized trial of silymarin for the treatment of Nonalcoholic steatohepatitis. Clin Gastroenterol Hepatol. 2017;15(12):1940-9.e8. https://doi. org/10.1016/j.cgh.2017.04.016

\section{PMid:28419855}

29. Cacciapuoti $F$, Scognamiglio $A$, Palumbo $R$, Forte $R$, Cacciapouti R. Silymarin in non alcoholic fatty liver disease. World J Hepatol. 2013;5(3):109-13.

PMid:23556042

30. Cho YK, Yun JW, Park JH, Kim HJ, Park DII, Sohn Cl, et al. Deleterious Effects of silymarin on the expression of genes controlling endothelial nitric oxide synthase activity in carbon tetrachloride-treated rat livers. Life Sci. 2009;85(7-8):281-90. https://doi.org/10.1016/j.lfs.2009.06.001 PMid:19527736

31. Mostafa RE, Zaki HF, Sleem AA, Salam O, Mossy FA, Kenawy SA. Pegylated interferon versus standard interferon and silymarin in treatment of liver fibrosis induced by chronic carbon tetrachloride in rats. Pharmacologia. 2013;4(3):208-17. https://doi.org/10.5567/pharmacologia.2013.208.217

32. Lee G, Jeong W, Jeong D, Do S, Kim T, Jeong K. Diagnostic evaluation of carbon tetrachloride-induced rat hepatic cirrhosis model. Anticancer Res. 2005;25(2A):1029-38. PMid: 15868943

33. Zitka O, Skalickova S, Gumulec J, Mosaic M, Adam V, Hubalex J, et al. Redox status expressed as GSH: GSSG ratio as a marker for oxidative stress in paediatric tumour patients. Oncol Lett. 2012;4(6):1247-53. https://doi.org/10.3892/ol.2012.931 PMid:23205122

34. Patel N, Joseph C, Corcoran GB, Ray SD. Silymarin modulates doxorubicin-induced oxidative stress, Bcl-xL and p53 expression while preventing apoptotic and necrotic cell death in the liver. Toxicol Appl Pharmacol. 2010;245(2):143-52. https://doi. org/10.1016/j.taap.2010.02.002

\section{PMid:20144634}

35. Fu Y, Zheng S, Lin J, Ryerse J, Cheng A. Curcumin protects the rat liver from $\mathrm{CCl}_{4}$-caused injury and fibrogenesis by attenuating oxidative stress and suppressing inflammation. Mol Pharmacol. 2008;73(2):399-409. https://doi.org/10.1124/mol.107.039818 PMid: 18006644

36. Kiruthiga PV, Pandian SK, Devi KP. Silymarin protects PBMC against $B(a) P$ induced toxicity by replenishing redox status and modulating glutathione metabolizing enzymes-an in vitro study. Toxicol Appl Pharmacol. 2010;247(2):116-28. https://doi. org/10.1016/j.taap.2010.06.004

PMid:20600218

37. Fallowfield JA. Therapeutic targets in liver fibrosis. Am J Physiol Gastrointest Liver Physiol. 2011;300(5):G709-15.

PMid:21233278

38. Liu T, Wang X, Karsdal MA, Leeming DJ, Genovese F. Molecular serum markers of liver fibrosis. Biomark Insight. 2012;7:105-17. https://doi.org/10.4137/bmi.s10009

PMid:22872786

39. Li CC, Hsiang CY, Wu SL, Ho TY. Identification of novel mechanisms of silymarin on the carbon tetrachloride-induced liver fibrosis in mice by nuclear factor- $\mathrm{KB}$ bioluminescent imaging-guided transcriptomic analysis. Food Chem Toxicol. 2012;50(5):1568-75. https://doi.org/10.1016/j.fct.2012.02.025 PMid:22386810

40. Iredale JP, Benyon RC, Pickering J, McCullen M, Northop M, Pawley S, et al. Mechanisms of spontaneous resolution of rat liver fibrosis. J Clin Invest. 1998;102(3):538-48. https://doi. org/10.1172/jci1018

PMid:9691091

41. Hemmann S, Graf J, Roderfeld M, Roeb E. Expression of MMPs and TIMPs in liver fibrosis-a systematic review with special emphasis on anti-fibrotic strategies. J Hepatol. 2007;46(5):955-75. https://doi.org/10.1016/j.jhep.2007.02.003 PMid: 17383048

42. Chen I, Chen Y, Chou C, Chuang R, Sheen L, Chiu C. Hepatoprotection of silymarin against thioacetamide-induced chronic liver fibrosis. J Sci Food Agric. 2012;92(7):1441-7. https://doi.org/10.1002/jsfa.4723

PMid:22102319

43. Giannandrea M, Parkx WC. Diverse functions of matrix metalloproteinases during fibrosis. Dis Model Mech. 2014;7(2):193-203. PMid:24713275

44. Uchinami H. Seki E, Brenner DA, D’ArmientoJ. Loss of MMP 13 attenuates murine hepatic injury and fibrosis during cholestasis. Hepatology. 2006;44(2):420-9. https://doi.org/10.1002/ hep. 21268 
PMid:16871591

45. Kawaguchi K, Sakaida I, Tsuchiya M, Omori K, Takami T, Okita K. Pioglitazone prevents hepatic steatosis, fibrosis, and enzyme-altered lesions in rat liver cirrhosis induced by a choline-deficient L-amino acid-defined diet. Biochem Biophys Res Commun. 2004;315(1):187-95. https://doi.org/10.1016/j. bbrc.2004.01.038

PMid:15013444

46. Lichtinghagen $R$, Bahr $M J$, Wehmeier $M$, Michels $D$, Haberkorn $\mathrm{Cl}$, Arndt $\mathrm{B}$, et al. Expression and coordinated regulation of matrix metalloproteinases in chronic Hepatitis $\mathrm{C}$ and Hepatitis C virus-induced liver cirrhosis. Clin Sci (Lond). 2003;105(3):373-82. https://doi.org/10.1042/cs20030098
PMid: 12760742

47. Endo H, Niioka M, Sugioka Y, Itoh J, Kameyama K, Okazaki I, et al. Matrix metalloproteinase-13 promotes recovery from experimental liver cirrhosis in rats. Pathobiology. 2011;78(5):23952. https://doi.org/10.1159/000328841

\section{PMid:21849805}

48. Knittel T, Mehde M, Kobold D, Saile B, Dinter C, Ramadori G. Expression patterns of matrix metalloproteinases and their inhibitors in parenchymal and non-parenchymal cells of rat liver: Regulation by TNF-alpha and TGF-beta1. J Hepatol. 1999;30(1):48-60. https://doi.org/10.1016/ s0168-8278(99)80007-5

PMid:9927150 